\title{
EMPOWERMENT VERSUS CHARITY IN BRINGING MICROFLUSH TOILETS TO THE POOR: SUSTAINABLE LOCAL ECONOMIES FOR THE COMMON GOOD
}

\author{
S. MECCA ${ }^{\dagger} \&$ A. AYALA \\ S-Lab, Department of Engineering-Physics-Systems, Providence College, USA. \\ $\uparrow$ Member of the Global Sustainable Aid Project (GSAP), globalsustainableaidproject.org.
}

\begin{abstract}
The GSAP (Grand Challenges Explorations Award) Microflush toilet system, a locally sourced-locally fabricated toilet that features a macro-organism enhanced aerobic filter-digester and an innovative valve that flushes on just $150 \mathrm{cc}$ of water has proven to be an effective sustainable sanitation solution for developing world tropical communities. This sustainable, locally sourced, locally fabricated technology has been deployed in 18 countries around the world through trained MAKERs creating for them a local business opportunity. The household toilet averages $\$ 300$ of which $\$ 100$ is profit for the MAKER. For the lowest income quintile households, a microloan is often required to effect toilet ownership and, when such credit is unavailable or inaccessible, GSAP's LENDER model, operated by the MAKER or by another community player becomes a viable solution. Recent data from this intervention suggests a more powerful investment model to empower multiple local MAKERs with a sustainable sanitation credit fund (SANCRED). GSAP's SANCRED approach as it evolved from its LENDER model is described. Early experience with essential elements of the model deployed with teams of Maasai women MAKERs is presented. The potential of the models, which emphasize economic development for the common good, solving the menacing condition of sanitation in the world and meeting Goal \#6 and several others of the UN Sustainable Development Goals (SDGs) are noted.

Keywords: closed systems, community development, economy for the common good, GSAP Microflush toilets, off-grid, revolving sanitation loan fund, rural wash, sanitation credit fund, sanitation, sustainable development goals, sustainable systemstoilets.
\end{abstract}

\section{BACKGROUND}

Under a Grand Challenges Explorations Award from the Bill \& Melinda Gates Foundation, GSAP (in Ghana known as the Ghana Sustainable Aid Project) successfully prototyped a marriage of two technologies: a filter-digester and the Microflush valve [1]. The valve, which was designed in the S-Lab in the Department of Engineering-Physics-Systems at Providence College flushes on as little as $150 \mathrm{cc}$ of reused water from the previous user's hand washing and results in an isolation of waste from human contact, eliminating odors and diseasebearing flies. GSAP has incorporated the valve into multiple designs including a generic macro-organism enhanced aerobic digester. The resulting GSAP Microflush (GMF) system has been designed in a model that is fabricated using local skills and local materials. So far, GSAP has trained and empowered local artisans as toilet MAKERs in 18 countries around the world. The entrepreneurial model is effecting reliable off-grid odor-free fly-free sanitation for thousands of households while creating sustainable enterprises for the MAKERs. Some of the trained MAKERs were masons and owned sufficient tools to begin their toilet making operations. Some were men and women, who did not even have the basic tools to begin their enterprise. Some of the latter were part of local cooperatives, who provided startup support and others were assisted by donor 'scholarships/grants/loans' from individuals or service organizations, e.g. Rotary. The typical grant is $\$ 500, \$ 100$ of which provides the required tools and $\$ 400$ purchases materials for the first two toilets. Upon demonstrated sale and completion of three toilets, the grant/loan is forgiven, and the new toilet MAKER has 
begun a sustainable enterprise of toilet sales with a balance of cash sales and sales with a loan. In communities with a preponderance of households in the bottom quintile of the household income spectrum, growth of the MAKER's enterprise (and satisfaction of community demand for the toilets) is limited by the proportion of MAKER proceeds that can be given over to small household toilet loans. In these conditions, the GSAP's LENDER or SANCRED programs offer great promise.

\section{REVIEW OF THE LENDER PROGRAM}

Soon after the publication of GSAP's LENDER model [2] readers asked what the minimum requirement is for funding a sustainable LENDER operation in a small community. The questions were provocative and the analyses that followed were revealing. The program can be placed in the hands of the MAKER or a separate entity; in either case the pro-formas are similar but depend on the expected mix of outright sales versus loan sales for the community. Paralleling the MAKER scholarship program, a \$2000 grant, of which $\$ 300$ takes care of some needed tools-a tablet or notebook computer and some paper forms, e.g. simple loan templates. The balance of the grant becomes the LENDER revolving loan fund from which toilet loans are made. The pro-forma depends on a number of factors especially the terms of the sale and household loan. For the model results shown in Fig. 1, the following assumptions were made:

\begin{tabular}{ll}
\hline Household microloan interest rate per annum & 0.2 \\
Toilet Price to the Household & $\$ 325$ \\
Gross Origination Fees per toilet to the LENDER & $\$ 50$ \\
Gross Profit per toilet to the MAKER & $\$ 75$ \\
Toilet Down Payment & $\$ 125$ \\
Loan amount & $\$ 200$ \\
Toilet Loans per month & 1.40 \\
\hline
\end{tabular}

We use parameters consistent with programs in Ghana. The $20 \%$ annual interest rate is about half of prevailing bank rates. However, in this model, there is a \$25 loan origination fee charged bringing the price of the toilet to $\$ 325$ (versus $\$ 300$ for a cash sale) and the MAKER foregoes $\$ 25$ of his/her profit as an incentive to the LENDER. A $\$ 125$ down payment is received and 24-month loan is written with monthly payments of $\$ 10.25$ of which the LENDER receives $\$ 1.25$ in compensation. This small initial return requires patience on the part of the LENDER until assets and loans reach significant levels to assure a larger self-payment.

The assets shown in Figure 1 maintain a 1.4 loans per month rate for the duration of the months shown. By month 50, some 70 loans have been made bringing toilets to over 1000 of the neediest people in the community. The more likely situation is that the new loan creation rates would gradually increase beginning around month 20 to take advantage of the growth of assets in the loan fund. A 3\% growth in toilet loans per month beginning in month 21 will result in a 5 year total of about 140 toilets serving more than 2000 people. LENDER profits which began at $\$ 83$ per month in month 1 will have reached $\$ 925$ by month 60 , well above median and average monthly salaries in the country. Bear in mind that the MAKER will have made outright cash sales in addition to sales involving the aforementioned loans. The 5-year results under this loan growth scenario are shown in Figure 2. 


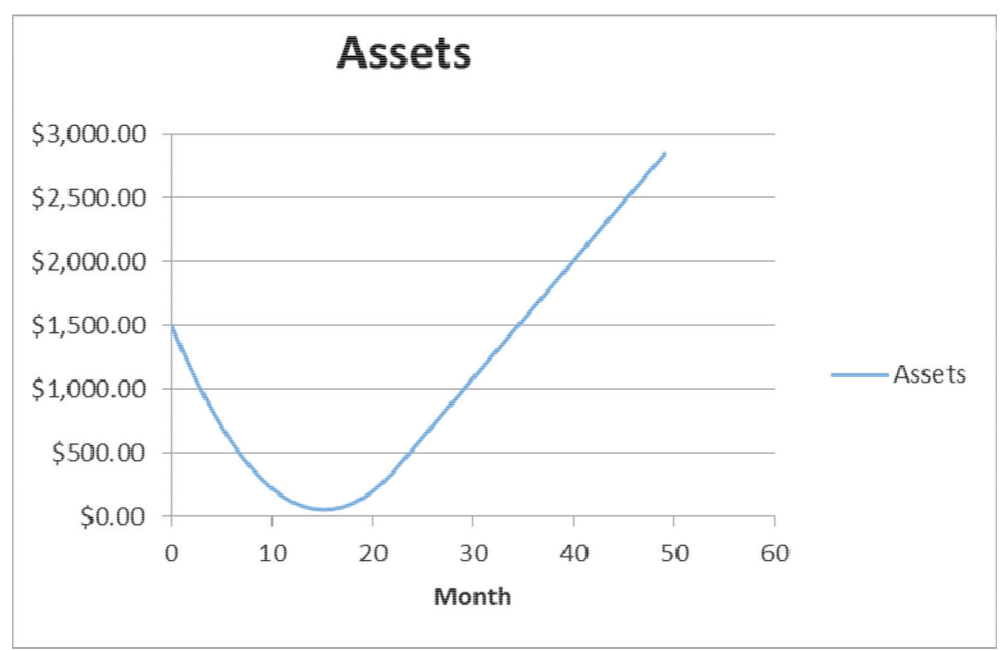

Figure 1: Fifty-month LENDER asset change for the conditions stated in the model (see text).

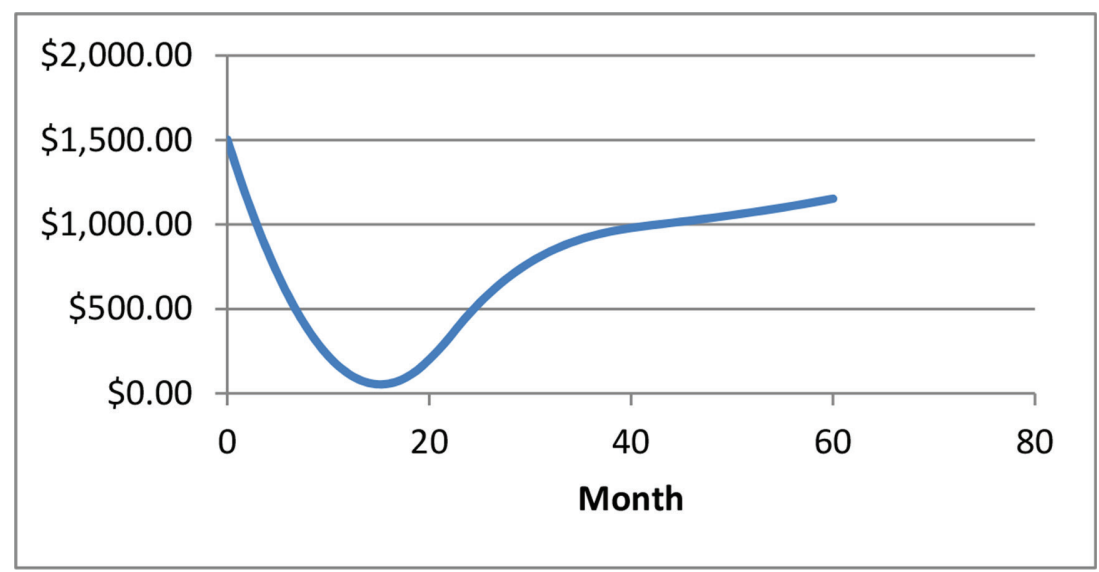

Figure 2: Five year asset changes for a 3\% increase in loan creation rate beginning in month 21.

With the help of donors, GSAP has created similar MAKER and LENDER models in rural communities in Ghana, Kenya, Uganda and Bolivia. Early reports suggest that the models are working. One 3 year program in Ghana has resulted in a large MAKER-LENDER enterprise that won a Changemaker award in the country. Two other very recent ones have resulted in multiple toilets per month. In Kenya, a 3 year old program has resulted in over 50 toilets with startup MAKER_LENDER total funding of just \$1500. In Kenya this program has spun off to create a MAKER_LENDER program with the Maasai in the southern part of the country. In Bolivia a similar program has begun with the Quechuan women in which GSAP has partnered with Procasha, an organization fostering women's cooperatives among this indigenous people. In the sections that follow, we will look more closely at the Maasai as a striking example of empowerment over charity and explore a final model for building local 
economies for the common good [3] in sanitation. That lesson should already be obvious in the foregoing examples. Startup funding in the foregoing example is $\$ 500$ for a MAKER and $\$ 2000$ for a LENDER or \$2500 for a MAKER_LENDER. That amount of money would have built eight toilets for needy households. Instead the MAKER-LENDER builds 140 toilets over 5 years all the while providing toilets for over 2000 people who otherwise would be practicing open defecation or using unhealthy undignified open latrines.

\section{LESSONS FROM THE MAASAI WOMEN}

In the first quarter of 2016 following a request from a spokesperson for women of the Maasai lands in southern Kenya made through GSAP's country director in Kenya, GSAP secured a multiphase grant to fund a MAKER and LENDER program for 14 Maasai women ( 7 teams of 3). The three phase project began immediately with the class training and acquisition of tools sets for each team, some of which are shown in Figure 3. This was followed by the identification of a field training site and the 5 day training of each team was carried out by GSAP's country director, who made multiple trips to the Maasai lands. Phase I-II of the program, which is described here, involved a $\$ 3750$ grant, the activities and cash flow from which are summarized in Tables 1 and 2, respectively.

Teams 1 through 5 were active in making loans with the funds they had and with some of their toilet sale proceeds; teams $6 \& 7$ completed 10 school block stalls; among teams $1-5,4$ toilets were built and sold for (cash) without loans. Going forward, as a result of their cooperation on the school block, teams $6 \& 7$ merged into one (which we now label as group 6). We observe the following from the toilet activities thus far:

- Average material costs are below the average of our global MAKERs. This is a result of lower costs for some superstructures, which are sometimes made using local customs from mud, dung and grass.

- The Maasai women are making a bit more profit per household stall. They are charging similar amounts for the household units, a bit less than the average for their school block stalls and realizing a bit less profit for the latter as well.

- Overall, they are well within the ranges of prices, and profits being realized elsewhere and a bit below on their material costs for the aforementioned reason.

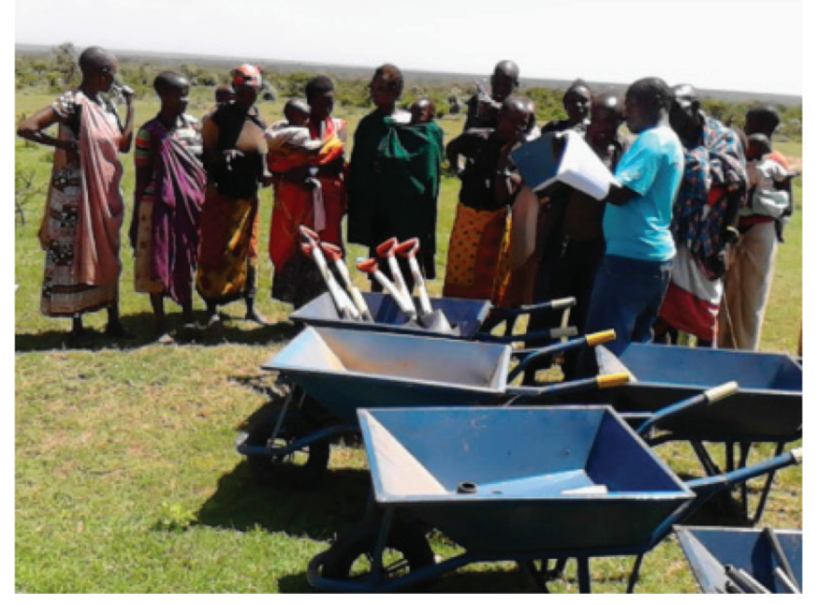

Figure 3: A few of the Maasai women toilet MAKERs receiving their tool sets. 
Table 1: The activities of the teams of Maasai women toilet MAKERs during the first quarter of their grant program.

\begin{tabular}{llllllll}
\hline $\begin{array}{l}\text { Group/ } \\
\text { Team }\end{array}$ & $\begin{array}{l}\text { Toilets Sold } \\
\text { (no loan) }\end{array}$ & $\begin{array}{l}\text { Toilets Sold } \\
\text { (w/loan) }\end{array}$ & $\begin{array}{l}\text { Sale } \\
\text { Amount }\end{array}$ & $\begin{array}{l}\text { Material } \\
\text { Cost }\end{array}$ & $\begin{array}{l}\text { Loan } \\
\text { amount }\end{array}$ & $\begin{array}{l}\text { Gross } \\
\text { Profit }\end{array}$ & $\begin{array}{l}\text { Payments } \\
\text { to date }\end{array}$ \\
\hline 1 & 1 & $\$ 300$ & $\$ 137$ & $\$ 200$ & $\$ 163$ & $\$ 115$ \\
2 & 1 & $\$ 300$ & $\$ 137$ & $\$ 200$ & $\$ 163$ & $\$ 92$ \\
3 & 3 & $\$ 900$ & $\$ 411$ & $\$ 600$ & $\$ 489$ & $\$ 136$ \\
4 & 2 & $\$ 300$ & $\$ 274$ & $\$ 400$ & $\$ 26$ & $\$ 180$ \\
5 & 1 & $\$ 300$ & $\$ 137$ & $\$ 200$ & $\$ 163$ & $\$ 46$ \\
$1-7$ as & 4 & 0 & $\$ 1,400$ & $\$ 548$ & $\$ 0$ & $\$ 852$ & $\mathrm{n} / \mathrm{a}$ \\
coop & & & $\$ 3,800$ & $\$ 1,750$ & $\$ 0$ & $\$ 2,050$ & $\mathrm{n} / \mathrm{a}$ \\
$\begin{array}{l}\text { School } \\
\text { stalls }\end{array}$ & 10 & & & & & & \\
$\begin{array}{l}\text { Totals } \\
\text { Average }\end{array}$ & 14 & 8 & $\$ 7,300$ & $\$ 3,394$ & $\$ 1,600$ & $\$ 3,906$ & $\$ 569$ \\
\hline
\end{tabular}

- It is interesting to note the collaboration of teams $6 \& 7$ resulting in a single entity.

- We did not expect the Maasai teams to be in a position to make any loans. The Kenya director encouraged them to set aside $75 \%$ of their profits for the loan fund. While this may not be the best long-term strategy (and in fact they may have had to pocket more than $25 \%$ of their profits), it is clear that they understand the revolving loan concept and the need for some restraint early on as they establish their enterprises. This is evident in the 8 toilet loans they made even at this early stage.

- We note from photos taken, the emerging high quality of the Maasai fabrications. As noted above, they make their own blocks from mud, dung and grass and their craftsmanship is remarkable looking at the final product.

It should be noted that the Maasai women are for the most part illiterate; few have more than a year or two of primary school education. Yet they have recognized the opportunity in their enterprise and are seizing on this accordingly. This is evident in both the aforementioned activities and in the cash flow shown in Table 2.

Again, a couple of things stand out:

- The expenditure for tool sets exceeds the average (\$100 per MAKER) for our programs in other countries. The carrying distance for heavy materials (cement, sand) is such that wheelbarrows were needed for each team; also, a drill and extra hex saw blades were purchased for each team.

- The profits and balance of funds in the Maasai account total $\sim 5520$. The balance of funds is $\$ 775$ so the 7 teams total return during this period was $\$ 4745$ or $\$ 431$ per team.

There are many lessons from this experience. First, if this followed the pattern of the longstanding model of humanitarian service, a charitable contribution for community sanitation of $\$ 3750$ (the phase I-II sum) could have given a school a 10 stall toilet block OR it could have purchased toilets for a dozen households. Instead it gave a business to 21 women, 
Table 2: The cash flow against the Phase I-II funding is shown in the table below.

\begin{tabular}{lcc}
\hline & Summary Transactions & Balance \\
\hline Phase l grant & $\$ 3,750$ & $\$ 3,750$ \\
Geoffrey travel & $-\$ 250$ & $\$ 3,500$ \\
Tools & $-\$ 855$ & $\$ 2,645$ \\
Materials & $-\$ 3,394$ & $-\$ 749$ \\
Toilet sales & $\$ 7,600$ & $\$ 6,851$ \\
Loans & $-\$ 1,600$ & $\$ 5,521$ \\
Payments & $\$ 569$ & $\$ 5,820$ \\
Maasai profits & $-\$ 4,206$ & $\$ 1,614$ \\
\hline
\end{tabular}

provided toilets for 12 households AND 10 school block stalls. There is still $\$ 775$ in the Maasai account ( 110 \$/team) and they have realized $\$ 431$ per team in profits. In fact, the worth of the enterprise already exceeds the phase I-II grant. Another lesson is that all of this is being accomplished by a collective of 21 illiterate indigenous women. GSAP has trained many women in several of the 18 countries in which it has worked and, while women MAKERs often organize themselves into teams (this helps in some of the more strenuous efforts-lifting slabs and such), their craftsmanship is excellent and their business skills (in spite of the lack of education) are responsible and amazing. The power of the coop also comes through in this experience and others like it. The message is clear as the social value expectations are being realized.

Phase III of the program, currently in place, is the establishment of a revolving loan fund in the sum of $\$ 14,300$. The fund will be administered through GSAP's Center in Kitale, Kenya but will eventually pass to the Maasai teams as they develop experience and training in lending and managing a loan fund. Investors in the Maasai and other GSAP MAKERLENDER programs, given the success of the programs, have now wondered about developing a sustainable investment model. We describe this in the next section.

\section{SUSTAINING A SANITATION CREDIT FUND (SANCREF) MODEL}

It is fair to ask whether or not Phase III monies are really needed for a project like the Maasai described in the previous section. Could the balance in their account and a portion of their proceeds sustain their individual enterprises? It is clear that this could be done but the rate of growth would be extremely slow and the demand for toilets would go unmet among poor households unless there is access to loan funds. One can envision a period where such loans are made from a Phase III grant loan and interest proceeds expand the fund, which continues to make household loans until such time as the MAKERs have sufficient resources and experience to make their own loans and realize the interest from same themselves. Enter the GSAP SANCREF model currently under development.

The SANCREF dynamics are shown in Fig. 4.

The fund would be expected to support the \$500 MAKER training grants previously discussed. MAKERs would sell toilets for cash and sell toilets with loans from the SANCREF fund underwritten to the households and co-signed by the MAKERs. One loan payment would be withheld from the MAKER to be returned as the last payment of the 


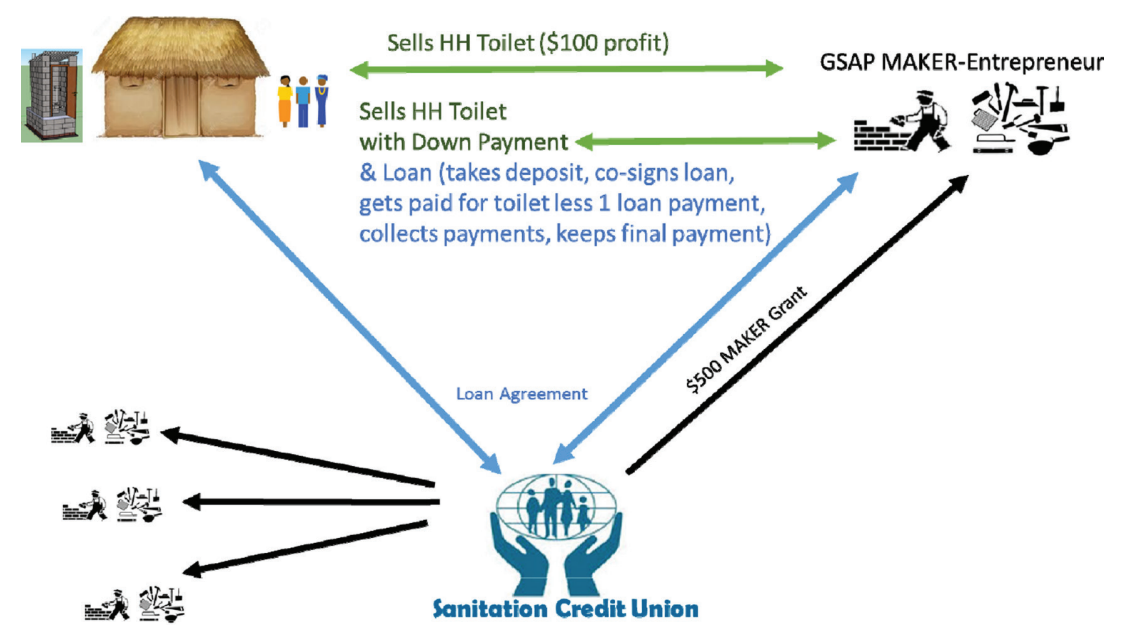

Figure 4: GSAP'ss SANCREF Model. See text.

loan. As the MAKERs' own assets grow, they would be expected to make their own loans and gradually leave the SANCREF. As the SANCREF's assets allow, it would fuel yet other MAKERs and the cycle would begin anew building a sustainable core from which nearby communities would realize GSAP's sustainable sanitation solution through new MAKERs with access to the SANCREF. While potential investors have suggested a return of the SANCREF's assets to the investor, GSAP believes the successive use of these funds within the region/country would create more social value in the successive programs than the value resulting from the extraction of those funds for re-investment in another region of the world. Further, an investment of just $\$ 2500$ in a SANCREF suggests that the additional management and tracking required for the eventual extraction of the fund creates effort and expense not unwarranted for such a small investment. GSAP expects to test this model against the more standard Maasai MAKER-LENDER program by rolling it out with women in the Samburu region in northern Kenya this year. This will provide a side by side long term comparison of the two systems each with teams of women from indigenous tribes in similar contexts.

\section{A PRACTICAL ISSUE}

There are many challenges to be overcome in implementing the SANCRED model, one of which is local tracking of toilet sales, loans and asset cash flow. The S-Lab at Providence College has worked on creating a web centric tracking system using an on-line, mobile-enabled, secure relational database having flexible field definition features to allow different types of data including images/photos, location, and bar code identification (if necessary). The system is depicted in Fig. 5 along with the type of data being tracked and reports supported.

While the system [5] is web-centric and mobile enabled, connection to the internet during the collection of data is not required. Collected data can be uploaded to the SANCRED cloud storage when the client (mobile device-smart phone) eventually does see internet service. This feature is important as many household systems are sold in regions where internet service is lacking. 

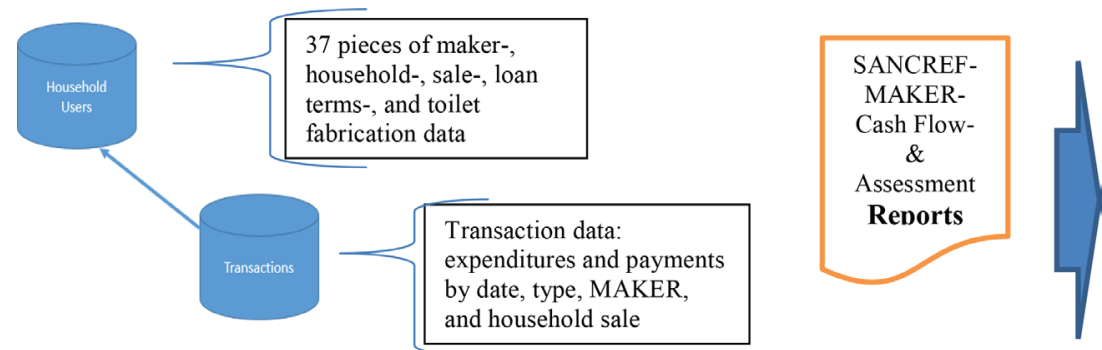

Figure 5: Two-file relational database tracking. 1. Household toilet sale and loan information and 2. Financial transactions. System reports include Detailed and Summary SANFREF- MAKER- Cash Flow- performance and program assessments.

\section{CONCLUDING REMARKS AND AN INTERESTING SPECULATION}

There is already evidence that GSAP's MAKER-LENDER models represent a sustainable way to bring its sustainable off-grid microflush toilet to developing communities around the world. The proposed SANCREF program has the potential to create a nuclear-breeder type solution to whole regions of communities with minimal financial outlay. It is interesting to speculate on the investment required in SANCREF programs to solve the menacing condition of sanitation in the world, meeting the UN's SDG Goal \#6 by 2030. An effective MAKER program can build 10-12 toilets per month serving 150-180 people with an effective household toilet. That's about 2000 people per year per MAKER. Assuming a need to serve half of a world population assumed to be $\sim 8 \mathrm{~B}$ by 2025 means we need toilets for 4B people; spread over 10 years, we need about $2 \mathrm{M}$ toilet MAKERs; at $\$ 500$ per MAKER and another \$2000 in SANCREF funding per first MAKER and realizing the sustainable (2-5 year) roll-over nature of SANCREF funds, \$1B is needed for MAKERs and conservatively another $\$ 2 \mathrm{~B}$ (assuming the 5 year roll-over) or a total of $\$ 3 \mathrm{~B}$ to meet SDG \#6 with a global deployment of this model. Alternatively, giving a toilet to needy households of the world, the old charity model, will require $\$ 300 /$ toilet $\times 4 \mathrm{~B}$ people $/ 15$ people/toilet or $\$ 120$ billion! Instead with the SANCREF program, at the end of 10 years the residual SANCREF funds will exceed the \$3B total investment that was made and it will have empowered 2 million MAKER enterprises- all local economies for the common good maintaining household and school toilets in the communities they serve. Of course, there are many factors left out of such ballpark estimates, but the fact that the sanitation problem appears solvable with an investment of less than $\$ 1$ per person to be served gives us hope in the empowerment model and encouragement to endure in our efforts to solve the menacing sanitation problem facing billions of people with an economy for the common good.

\section{ACKNOWLEDGEMENTS}

The authors acknowledge the efforts of GSAP Country Director in Kenya, Geoffrey Nyakundi, and express our gratitude to the nonprofit organizations: Global Sustainable Aid Project for its overall support and Women in Social Entrepreneurship for its financial support of the Maasai project. 


\section{REFERENCES}

[1] Mecca, S., Davis, H. \& Davis, A., The Microflush/Biofil System: Results to Date of Prototype Installations in Ghana. Fecal Sludge Management FSM2 Conference, Durban, 2012.

[2] Mecca, S., Davis, H. \& Davis, A., Application of GSAP Microflush toilets: a sustainable development approach to rural and peri-urban sanitation. WIT Transactions Ecology and the Environment, 175, 2013.

[3] Felber, C., Change Everything: Creating an Economy for the Common Good, (English translation from the German original), Zed Books Ltd, Unit 28 The Foundry, London, 2015.

[4] United Nations Sustainable Development Goals. Available at: http://www.un.org/sustainabledevelopment/sustainable-development-goals, September 15, 2015.

[5] EpiCollect.net is a Beta database product developed by Imperial College London. 